ДЕФЕКТЫ ОКАЗАНИЯ МЕДИЦИНСКОЙ ПОМОЩИ ПАЦИЕНТАМ С ОСТРЫМ КОРОНАРНЫМ СИНДРОМОМ С ПОДЪЕМОМ СЕГМЕНТА ST, НЕ ПОДВЕРГШИМСЯ РЕПЕРФУЗИОННОЙ ТЕРАПИИ

(C) В.В. Колосова ${ }^{1}$, К.А. Мосейчук ${ }^{1}$, Е.Н. Паршикова ${ }^{2}$, А.А. Пыко ${ }^{1}$, О.М. Урясьев ${ }^{1}$, Е.В. Филиппов 1

Рязанский государственный медицинский университет имени академика И.П. Павлова, Рязань, Российская Федерация (1)

Люберецкая районная больница №1, Люберцы, Российская Федерация (2)

Цель. Оценка дефектов оказания медицинской помощи у пациентов с острым коронарным синдромом с подъемом сегмента ST, не получивших реперфузионную терапию.

Материалы и методы. В исследование включались пациенты с острым коронарным синдромом с подъемом сегмента ST, госпитализированные в первичные сосудистые отделения и региональные сосудистые центры региона, не получившие реперфузионную терапию. Проводился анализ медицинских карт стационарного больного.

Результаты. В исследование было включено 113 пациентов, соответствующих критериям включения, из них 56,6\% - мужчины. Средний возраст составил - 70,3 2 2,8 лет. Наиболее частыми жалобами пациентов во время госпитализации в стационар были боли за грудиной, одышка, слабость, тошнота и холодный пот. Большинство пациентов имели коморбидную патологию: артериальная гипертензия, хроническая сердечная недостаточность и стабильная стенокардию. Реперфузионная карта заполнялась медицинскими работниками в 47,8\% случаев. У 26,5\% причина отказа от реперфузионной терапии по данным медицинской документации не установлена. Нагрузочная доза антитромбоцитарных препаратов использовалась в 76,1\% случаев. Антикоагулянтная парентеральная терапия проводилась в 90,2\% случаев. За время нахождения в стационаре маркеры повреждения миокарда определялись только у 75,2\% пациентов. Обращает на себя внимание низкая частота проведения ЭхоКГ в первые 24 часа - 12,4\%. Несмотря на высокую частоту назначений основных групп препаратов во время госпитализации, при выписке частота этих назначений снижалась. Коронароангиография при выписке была рекомендована лишь 20,4\% пациентов.

Заключение. У пациентов с острым коронарным синдромом с подъемом сегмента ST, не получивших реперфузионную терапию, выявлены дефекты оказания медицинской помощи, которые могли повлиять на прогноз. Полученные данные требуют проведения дальнейших исследований и должны быть учтены при разработке образовательных программ для врачей-кардиологов, специалистов скорой медицинской помощи и анестезиологов-реаниматологов.

Ключевые слова: острый коронарный синдром; дефекты оказания медицинской помощин; реперфузия; антиагрегантная терапия; коронароангиография. 


\title{
DEFECTS OF PROVIDING MEDICAL CARE TO PATIENTS WITH ST SEGMENT ELEVATION ACUTE CORONARY SYNDROME WHO DID NOT RECEIVE REPERFUSION THERAPY
}

\author{
V.V. Kolosova ${ }^{1}$, K.A. Moseichuk ${ }^{1}$, E.N. Parshikova ${ }^{2}$, A.A. Pyko ${ }^{1}$, O.M. Uryasyev ${ }^{1}$, \\ E.V. Filippov ${ }^{1}$
}

Ryazan State Medical University, Ryazan, Russian Federation (1) Lubertsy Regional Hospital №1, Lubertsy, Russian Federation (2)

\begin{abstract}
Aim. Assess defects in the provision of medical care to patients with ST segment elevation acute coronary syndrome, who did not receive reperfusion therapy.

Materials and Methods. The study included patients with acute coronary syndrome with ST segment elevation who did not receive reperfusion therapy being hospitalized to the primary vascular units. The analysis of medical records of hospitalized patients was carried out.

Results. The study included 113 patients who satisfied the inclusion criteria, of which $56.6 \%$ were men. The average age was $70.3 \pm 2.8$ years. The most common complaints of patients were chest pain, shortness of breath, weakness, nausea and cold sweat. Most patients had comorbid pathology: arterial hypertension, chronic heart failure, and stable angina pectoris. The reperfusion card was filled out by medical personnel in $47.8 \%$ of cases. In $26.5 \%$, the reason for rejection of reperfusion therapy was not clear from the medical records. A loading dose of antiplatelet drugs was used in $76.1 \%$ of cases. Anticoagulant parenteral therapy was carried out in $90.2 \%$ of cases. During stay in hospital, markers of myocardial damage were determined only in $75.2 \%$ of patients. Noteworthy is the low frequency of implementation of echocardiography in the first 24 hours $-12.4 \%$. Despite the high frequency of administrations of the main groups of medical drugs during hospitalization, on discharge from hospital the number of administrations decreased. On discharge, coronary angiography was recommended to only $20.4 \%$ of patients.

Conclusion. In patients with acute coronary syndrome with ST segment elevation, who did not undergo reperfusion therapy, defects in the provision of medical care were found that could affect the prognosis. The data obtained require further study and should be taken into account in development of educational programs for cardiologists, emergency medical specialists, and anesthesiologists-resuscitationists.
\end{abstract}

Keywords: acute coronary syndrome; defects in the provision of medical care; reperfusion; antiplatelet therapy; coronary angiography.

Смертность от болезней системы кровообращения (БСК) и, в частности, ишемической болезни сердца (ИБС), в Российской Федерации и Центральном федеральном округе (ЦФО) постепенно снижается (рис. 1) $[1,2]$. Однако, темпы уменьшения данных показателей остаются все еще недостаточными. Одной из причин, которая продолжает «удерживать» смертность на довольно высоком уровне, является оказание медицинской помощи с дефектами, как на догоспитальном, так и на госпитальном этапе.
Так, по данным Института медицины США вследствие предотвратимых медицинских дефектов больницах страны ежегодно погибает от 44 до 98 тыс. человек. По этому показателю врачебные ошибки занимают 8-е место в списке основных причин смерти Факторами, которые могли бы повлиять на вероятность неблагоприятного исхода являются: несвоевременность медицинского вмешательства, неправильность и неадекватность выбора метода лечения, состояние больного в момент поступления, 
особенности течения заболевания, качество диагностики, квалификация врача, уровень знаний, стаж работы по специальности, эмоциональное состояние, неуверенность или, наоборот, излишняя самоуверенность, физическая выносливость и т.д. [3].

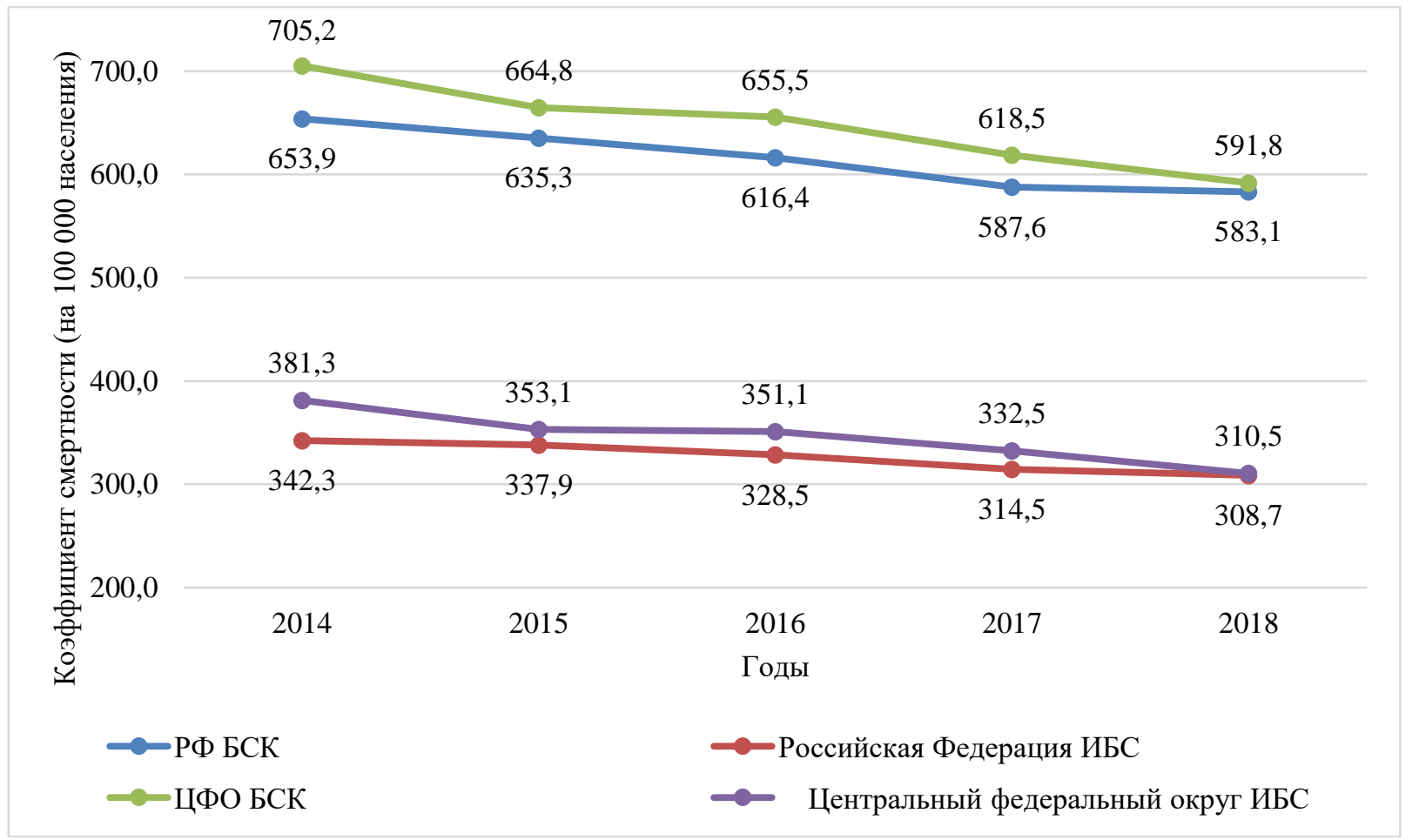

Рис. 1. Коэффициенты смертности от болезней системы кровообращения и ишемической болезни сердца в Российской Федерации и ЦФО

Ошибки на догоспитальном этапе связаны не только с действиями бригад скорой медицинской помощи, но и с оказанием помощи на поликлиническом этапе [4]. Стационарный этап целесообразно также разделить на 2 уровня: приемный покой и кардиологическое отделение. Учитывая, что подавляющее большинство пациентов с острым коронарным синдромом (ОКС) госпитализируется в «инфарктную» сеть (первичные сосудистые отделения (ПСО) и региональные сосудистые центры (РСЦ)), рассмотрение дефектов оказания медицинской помощи на этом этапе и их коррекция являются одним из важных элементов снижения риска смерти и неблагоприятных исходов у пациентов.

Цель - оценить дефекты оказания медицинской помощи у пациентов с острым коронарным синдромом с подъемом сегмента ST (OKCпST), не получивших реперфузионную терапию.

\section{Материалы и методы}

В пилотное исследование включались пациенты с OKCпST, госпитализированные в ПСО и РСЦ региона, не получившие реперфузионную терапию (тромболизис или чрезкожное коронарное вмешательство (ЧКВ)) за 6 месяцев 2019 года. Включение в исследование пациентов было сплошным, с 01 января по 30 июня 2019 года.

Критериями включения в исследование были:

1. Возраст 18 лет и старше.

2. Клиника острого коронарного синдрома со стойким подъемом сегмента ST.

3. На догоспитальном этапе и за время госпитализации реперфузионная терапия не проводилась. региона.

4. Госпитализация в ПСО или РСЦ

5. Диагноз при выписке соответствовал коду МКБ-10 I21.

Критериев исключения не было. 
Прямого контакта между исследователями и пациентами не было. Проводился только анализ медицинских записей (медицинских карт стационарного больного). Данные заносились в разработанную индивидуальную регистрационную карту, после чего верифицировались независимыми исследователями.

Статистическая обработка полученных результатов осуществлялась с помощью пакета прикладных статистических программ Excel 2016 (MS Corporation, США) и пакета прикладных программ SPSS 22 («SPSS: An IBM Company», США).

Результаты и их обсуждение

Население Рязанской области, по данным Рязстата, на 1 января 2020 года и в среднем за 2019 год составило 1108847 человек. В области имеется 6 ПСО и 2 РСЦ. При этом в г. Рязани (население 539290 человек) расположены 2 РСЦ и 1 ПСО с возможностью выполнения ЧКВ [5]. За 2019 год в «инфарктную» сеть был госпитализирован 1581 пациент с OKСпST, из них 1341 - в первые 24 часа и 1107 - в первые 12 часов.

В исследование было включено 113 пациентов, соответствующих критериям включения, что составило 8,7\% всех пациентов, госпитализированных с ОКСпST в первые 24 часа. Клиническая характеристика пациентов представлена в таблице 1. В исследование было включено 56,6\% лиц мужского пола, средний возраст составил - 70,3 $\pm 2,8$ лет. Наиболее частыми жалобами пациентов во время госпитализации в стационар были боли за грудиной $(90,3 \%)$, одышка $(52,2 \%)$, слабость $(39,8 \%)$, тошнота $(7,0 \%)$ и холодный пот $(4,4 \%)$. Большинство пациентов (более 90\%) с OKCпST, не подвергшихся реперфузии, имели коморбидную патологию. Наиболее часто в этой группе встречалась артериальная гипертензия $(92,9 \%)$, хроническая сердечная недостаточность $(81,4)$ и стабильная стенокардия $(40,7 \%)$.

Таблица 1

\section{Клиническая характеристика пациентов с ОКСnST, включенных в исследование}

\begin{tabular}{|l|l|}
\hline \multicolumn{1}{|c|}{ Характеристика пациентов } & \multicolumn{1}{c|}{$\%(\mathbf{n})$} \\
\hline Мужчины & $56,6(64)$ \\
\hline Средний возраст, лет & $70,3 \pm 2,8$ \\
\hline $30-39$ лет & $0,8(1)$ \\
\hline $40-49$ лет & $4,4(5)$ \\
\hline $50-59$ лет & $14,1(16)$ \\
\hline $60-69$ лет & $29,1(33)$ \\
\hline $70-79$ лет & $21,2(24)$ \\
\hline $80-90$ лет & $30,0(34)$ \\
\hline \multicolumn{2}{|c|}{ Сопутствующая патология } \\
\hline Стабильная стенокардия в анамнезе & $40,7(46)$ \\
\hline Инфаркт миокарда в анамнезе & $30,9(35)$ \\
\hline Артериальная гипертония & $92,9(105)$ \\
\hline Хроническая сердечная недостаточность & $81,4(92)$ \\
\hline Сахарный диабет & $30,9(35)$ \\
\hline Нарушения ритма сердца & $31,9(36)$ \\
\hline Хронические заболевания желудочно-кишечного тракта & $9,7(11)$ \\
\hline
\end{tabular}

На догоспитальном этапе тромболитическая терапия данной группе пациентов не проводилась, реперфузионная карта не заполнялась. На госпитальном этапе реперфузионная карта заполнялась медицинскими работниками в $47,8 \%$ случаев. Во всех этих случаях, согласно заполненной карте, проведение тромболитической терапии не было показано.

При детальном анализе медицинских записей пациентов было установлено, что ЭКГ-критерии проведения тромболизиса имелись у всех пациентов. У 34\% (38 человек) давность болевого 
синдрома была менее 12 часов, однако, у 26,5\% (30 человек) причина непрове- дения реперфузионной терапии не установлена (рис. 2).

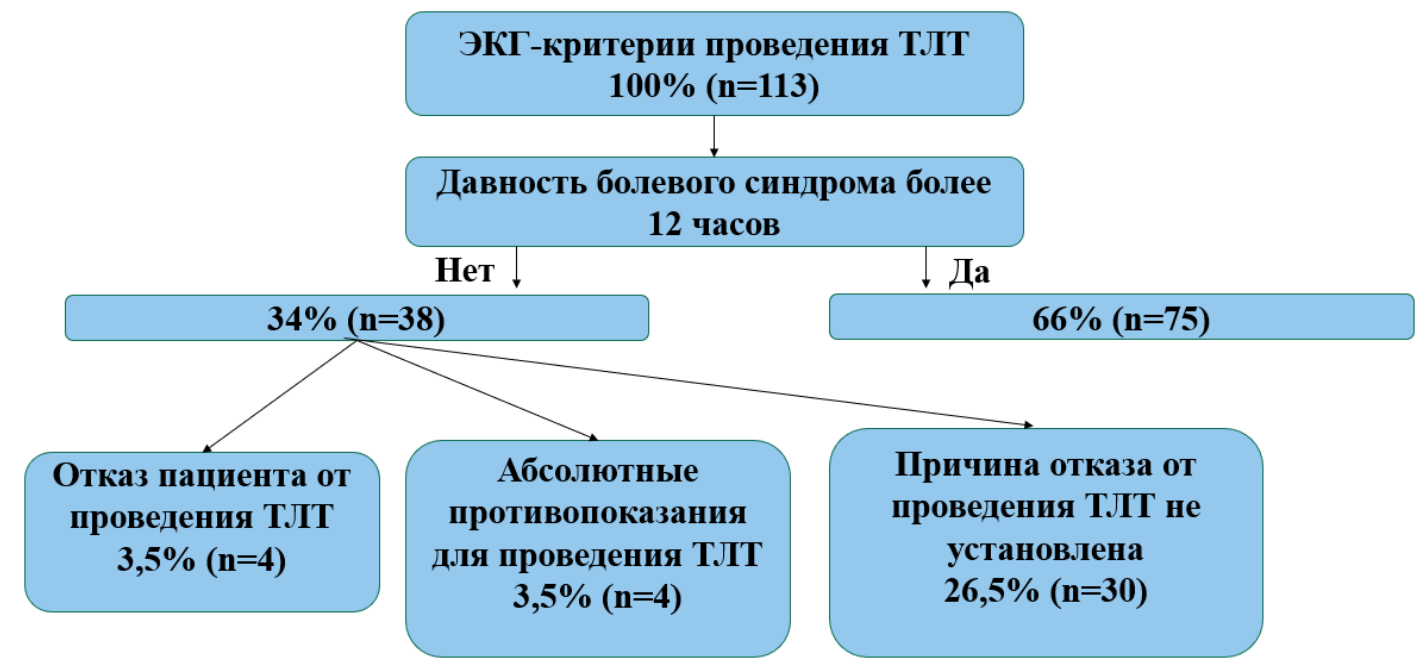

Примечание: ТЛТ - тромболитическая терапия

Рис. 2. Причины непроведения тромболитической терапии у пациентов

Нагрузочная доза антитромбоцитарных препаратов использовалась в 76,1\% случаев. При этом доза клопидогреля 300 мг и более назначалась в $69,9 \%$, а тикагрелора - в 6,2\% случаев. Нагрузочная доза аспирина использовалась у $62,7 \%$ пациентов.

Антикоагулянтная парентеральная терапия проводилась в 90,2\% случаев. При этом в 52,0\% случаев использовался подкожно нефракционированный гепарин (НФГ), в $15,2 \%$ - внутривенно НФГ и в 5,3\% - внутривенно НФГ с последующим переходом на подкожное введение. Низкомолекулярный гепарин использовался у $17,7 \%$ пациентов.

За время нахождения в стационаре маркеры повреждения миокарда определялись только у 75,2\% пациентов. При этом уровень тропонинов определялся у 75,2\% пациентов, МВ-КФК - у 61,1\%. Оценка липидного спектра проводилась в $86,7 \%$ случаев, в основном по общему холестерину $(86,7 \%)$. Уровень липопротеинов низкой плотности оценивался только в $61,9 \%$ случаев, а липопротеидов высокой плотностиеще реже $(36,3 \%)$. Сопутствующее определение креатинина и скорости клубочковой фильтрации проводилось в 75,6\%, функции печени $-87,6 \%$ случаев (табл. 2 ).
Инструментальные исследования пациентам с OKCпST преимущественно проводились не в первые 24 часа, а в последующие дни, за исключением ЭКГ, которая выполнялась в 100\% при поступлении в стационар. Обращает на себя внимание низкая частота проведения ЭхоКГ в первые 24 часа - 12,4\%, а также то, что 10,6\% пациентов она не была проведена вообще в течение госпитализации.

11 (9,7\%) пациентам была проведена коронароангиография (КАГ) в течение госпитализации, однако, у 3 из них не было выявлено гемодинамически значимых стенозов коронарных артерий, а у 8 было либо многососудистое поражение (6 пациентов), что требовало коронарного шунтирования, либо вмешательство было предпринято, но попытка была неудачной (2 пациента).

При анализе медикаментозной терапии было выявлено, что подавляющее большинство пациентов получали двойную антитромбоцитарную терапию $92,9 \%$, статины - 99,2\%, бета-блокаторы $94,1 \%$, ингибиторы ангиотензинпревращающего фермента (иАПФ) и блокаторы рецепторов ангиотензина (БРА) - 98,4\%, оральные антикоагулянты - 7,9\% (табл. 3). 
Обследование пациентов с ОКСnST за время госпитализации

\begin{tabular}{|l|c|}
\hline \multicolumn{1}{|c|}{ Обследование } & \% \\
\hline Общий анализ крови & 99,1 \\
\hline Тропонины* & 75,2 \\
\hline КФК & 69,0 \\
\hline МВ-КФК & 61,1 \\
\hline ОХС & 86,7 \\
\hline ЛПНП & 61,9 \\
\hline ЛПВП & 36,3 \\
\hline ТГ & 74,3 \\
\hline Креатинин & 75,6 \\
\hline СКФ & 75,6 \\
\hline АЛТ & 87,6 \\
\hline АСТ & 86,2 \\
\hline \multicolumn{2}{|c|}{ Инструментальное обследование } \\
\hline ЭКГ \\
\hline ЭхоКГ в течение госпитализации & 100,0 \\
\hline ЭхоКГ в первые 24 часа & 89,4 \\
\hline КАГ в течение госпитализации _2,4 \\
\hline \multicolumn{2}{|c|}{9,7} \\
\hline
\end{tabular}

Примечание: * учитывались все типы тропонинов; КФК - креатинфосфокиназа; МВ-КФК - МВ фракция креатинфосфокиназы; ОХС - общий холестерин; ЛПНП - липопротеины низкой плотности; ЛПВП - липопротеины высокой плотности; ТГ - триглицериды; СКФ - скорость клубочковой фильтрации; АЛТ - аланинаминотрансфераза; АСТ - аспартатаминотрансфераза; ЭКГ - электрокардиография; ЭхоКГ - эхокардиография; КАГ - коронароангиография

Таблица 3

\section{Медикаментозная терапия пациентов с ОКСnST в стационаре}

\begin{tabular}{|l|c|}
\hline \multicolumn{1}{|c|}{ Препарат } & \% \\
\hline Антиагрегантная терапия & $\mathbf{9 9 , 0}$ \\
\hline Аспирин & 92,9 \\
\hline Клопидогрель & 91,1 \\
\hline Тикагрелор & 7,9 \\
\hline Статины & $\mathbf{9 9 , 2}$ \\
\hline Симвастатин 40 мг/сут & 1,0 \\
\hline Аторвастатин 10 мг/сут & 3,7 \\
\hline Аторвастатин 20 мг/сут & 30,5 \\
\hline Аторвастатин 40 мг/сут & 49,0 \\
\hline Розувастатин 10 мг/сут & 13,0 \\
\hline Розувастатин 20мг/сут & 1,0 \\
\hline Розувастатин 40 мг/сут & 1,0 \\
\hline Бета-блокаторы & $\mathbf{9 4 , 1}$ \\
\hline Метопролол & 79,4 \\
\hline Бисопролол & 8,8 \\
\hline Карведилол & 5,9 \\
\hline ИАПФ и БРА & $\mathbf{9 8 , 4}$ \\
\hline Эналаприл & 57,8 \\
\hline Лизиноприл & 29,3 \\
\hline Периндоприл & 2,7 \\
\hline Каптоприл & 2,7 \\
\hline Зофеноприл & 1,8 \\
\hline Фозиноприл & 1,0 \\
\hline Валсартан & 2,1 \\
\hline Лозартан & 1,0 \\
\hline Оральные антикоагулянты & $\mathbf{7 , 9}$ \\
\hline Варфарин & 5,3 \\
\hline Прямые пероральные антикоагулянты \\
\hline
\end{tabular}


Несмотря на высокую частоту назначений основных групп препаратов во время госпитализации, при выписке частота этих назначений снижалась (рис. 3).
КАГ была рекомендована 20,4\% пациентов. Общие рекомендации были представлены у всех пациентов, рекомендации по наблюдению кардиолога - 17,8\% случаев.

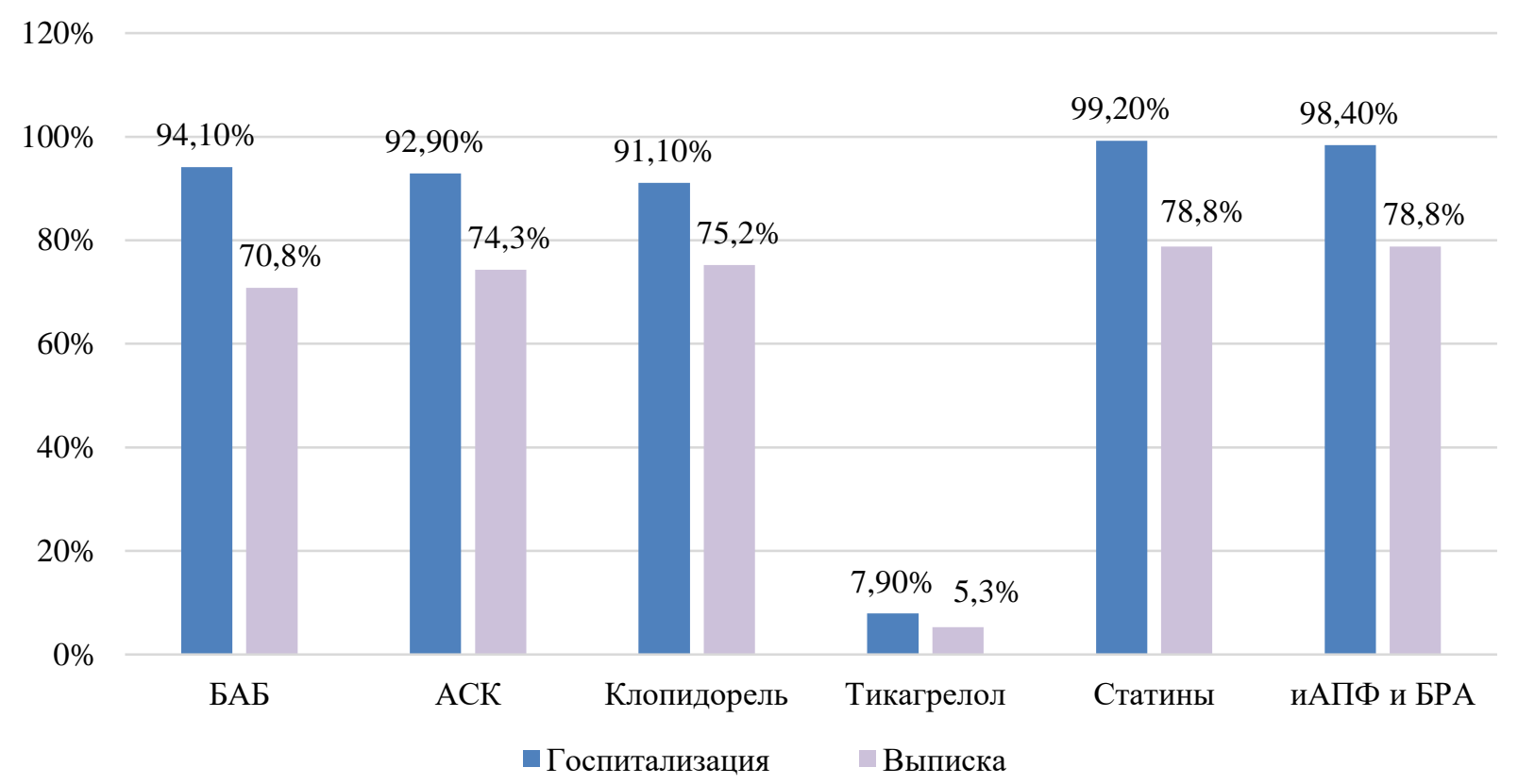

Примечание: БАБ - бета-адреноблокаторы, АСК - ацетилсалициловая кислота, ИАПФ - ингибиторы ангиотензипревращающего фермента, БРА - блокаторы рецепторов ангиотензина-2

Рис. 3. Частота назначений различных групп лекарственных препаратов у пациентов с OKCпST во время госпитализации и при выписке

Исследование показывает, что пациенты с OKСпST, которым не проводилась реперфузионная терапия, имеют большое количество дефектов оказания медицинской помощи. Попытки оценки таких дефектов делались и ранее. Однако в этих исследованиях оценивались дефекты у всех пациентов с инфарктом миокарда или острым коронарным синдромом [6-7]. Сергеев Ю.Д. с соавт. (2007) отмечает, что при анализе неблагоприятных исходов, наступивших при оказании медицинской помощи, в $82,7 \%$ случаев были выявлены дефекты [8]. В то же самое время в целом в группе пациентов с ОКС их частота не превышала 2,1\% [7].

В нашем исследовании у пациентов с OKCпST без реперфузионной терапии отмечается высокий уровень непроведенных тромболизисов пациентам, которым он был показан (согласно медицинским записям) - 26,5\% случаев. Кроме того, существенной проблемой было снижение частоты назначения показанных лекарственных препаратов при выписке по сравнению с принимаемой терапией в стационаре. В проведенных ранее исследованиях показано, что при выписке у пациентов с ОКС частота назначения «обязательной» терапии не ниже, чем за время госпитализации $[9,10]$. Полученные нами данные требуют дополнительного анализа, в том числе и с позиций фармакоэкономики. Также КАГ, являясь обязательной процедурой для всех пациентов с ОКСпST, не рекомендована при выписке в 79,6\% случаев [11].

В процессе госпитализации далеко не всем сделана ЭхоКГ, что может свидетельствовать о недостаточном количестве ап- 
паратов или врачей функциональной диагностики. Такие же данные получены и по разделу лабораторных исследований. Только 61,9\% пациентов был определен уровень липопротеинов низкой плотности и у $75,6 \%$ - скорость клубочковой фильтрации.

Наиболее часто используемым статином у пациентов с OKСпST без реперфузионной терапии был аторвастатин, однако, максимальная доза, используемая у данной группы пациентов, не превышала 40 мг/сут. Розувастатин использовался значительно реже, частота его назначения не превышала 15\%.

Среди иАПФ использовались в основном препараты, требующие их назначения 2 раза в сутки, БРА практически не использовались у данной группы пациентов, что не соответствовало данным предыдущих исследований, которые включали, как лиц, перенесших ОКС, так и лиц со стабильной ИБС $[12,13]$. Среди бета-блокаторов наиболее популярным был метопролол, что также отличало полученные данные от более ранних исследований, где более чем в половине случаев использовался бисопролол (62,1\%, по данным РЕКВАЗА) [14,15].

Следует отметить, что полученные данные невозможно «напрямую» сравнивать с другими исследованиями, поскольку в них имелись принципиально другие критерии включения. Полученные данные в рамках пилотного проекта требуют изучения и дальнейших исследований. Выявленные дефекты требуют разработки образовательных программ, направленных на их недопущение в будущем.

\section{Заключение}

Таким образом, у пациентов с $\mathrm{OKCпST,} \mathrm{не} \mathrm{получивших} \mathrm{реперфузионную}$ терапию, выявлены дефекты оказания медицинской помощи, которые могли повлиять на прогноз (в 26,5\% случаев тромболитическая терапия не проведена при наличии показаний и отсутствии противопоказаний).

Частота назначений рекомендованных препаратов после OKCпST при выписке была ниже, чем во время госпитализации, что также может быть ассоциировано с неблагоприятными исходами. Полученные данные требуют проведения дальнейших исследований и должны быть учтены при разработке образовательных программ для врачей-кардиологов, специалистов скорой медицинской помощи и анестезиологов-реаниматологов.

\section{Дополнительная информация}

Конфликт интересов. Авторы декларируют отсутствие явных и потенциальных конфликтов интересов, о которых необходимо сообщить в связи с публикацией данной статьи.

Этика. В исследовании использованы данные людей в соответствии с подписанным информированным согласием.

Финансирование. Исследование не имело спонсорской поддержки.

Ограничения. Данные получены из медицинских карт стационарного больного ПСО/РСЦ, что может повлиять на корректность определения причины непроведения реперфузионной терапии.

\section{Участие авторов:}

Концепция и дизайн исследования, написание текста - Филиппов Е.В.

Сбор материала - Колосова В.В., Мосейчук К.А.

Анализ полученных данных - Колосова В.В., Мосейчук К.А., Пыко А.А., Урясьев О.М.

Сбор материала, анализ полученных данных, написание текста - Паршикова Е.Н.

\section{Литература}

1. Коэффициенты смертности по основным классам причин смерти. Доступно по: https://rosstat.gov. ru/bgd/regl/B09_16/IssWWW.exe/Stg/6-08.htm. Ссылка активна на 06 июня 2020.

2. Данилов А.В., Кобзарь И.И., Нагибин О.А., и др. Заболеваемость и смертность от сердечно-сосудистых заболеваний в Рязанской области: 20142018 гг. // Наука молодых (Eruditio Juvenium). 2019. T. 7, №3. C. 439-449. doi:10.23888/HMJ 201973439-449
3. Шарабчиев Ю.Т. Врачебные ошибки и дефекты оказания медицинской помощи: социально-экономические аспекты и потери общественного здоровья // Международные обзоры: клиническая практика и здоровье. 2013. №6. С. 14-31.

4. Переверзева К.Г., Воробьев А.Н., Никулина Н.Н., и др. Особенности обследования паци-ентов с ишемической болезнью сердца в амбулаторной практике по данным регистрового наблюдения // Российский медико-биологический вестник имени академика И.П. Павлова. 
2014. №1. C. 90-96.

5. Оценка численности постоянного населения Рязанской области на 1 января 2020 года и в среднем за 2019 год. Доступно по: https://ryazan.gks.ru/storage/mediabank/Оценка\%20численности \%20постоянного \%20населения $\% 20$ Рязанской\%20области\% $\%$ 20на\% $201 \% 20$ января\%2020 20\%20года.pdf. Ссылка активна на 06 июня 2020.

6. Moy E., Barrett M., Coffey R., et al. Missed diagnoses of acute myocardial infarction in the emergency department: variation by patient and facility characteristics // Diagnosis. 2015. Vol. 2, №1. P. 29-40. doi:10.1515/dx-2014-0053

7. Сергеев Ю.Д., Бисюк Ю.В., Вериковский В.А. Дефекты оказания медицинской помощи пациентам с острым коронарным синдромом (медико-правовые аспекты проблемы) // Медицинское право. 2019. №3. С. 31-38.

8. Сергеев Ю.Д., Бисюк Ю.В. О некоторых дефектах диагностики и их причинах при оказании экстренной кардиологической помощи // Кардиоваскулярная терапия и профилактика. 2007. T. 7, №7. C. 67-70.

9. Steg P.G., Goldberg R.G., Gore J.M., et al. Baseline characteristics, management practices, and in-hospital outcomes of patients hospitalized with acute coronary syndromes in the Global Registry of Acute Coronary Events (GRACE) // American Journal of Cardiology. 2002. Vol. 90, №4. P. 358-363. doi:10.1016/s0002-9149(02)02489-x

10. Kaul U., Sethi K.K., Dalal J., et al. A multicentre retrospective study to understand anti-platelet treatment patterns and outcomes of acute coronary syndrome patients in India (TRACE) // Indian Heart Journal. 2014. Vol. 66, №3. P. 334-339. doi:10. 1016/j.ihj.2014.03.009

11. Клинические рекомендации «Острый инфаркт миокарда с подъемом сегмента ST электрокардиограммы». 2020. Доступно по: https://scardio. ru/content/Guidelines/2020/Clinic_rekom_OKS_s ST.pdf. Ссылка активна на 06 июня 2020.

12. Бойцов С.А., Лукьянов М.М., Якушин С.С., и др. Регистр кардиоваскулярных заболеваний (РЕКВАЗА): диагностика, сочетанная сердечнососудистая патология, сопутствующие заболевания и лечение в условиях реальной амбулаторно-поликлинической практики // Кардиоваскулярная терапия и профилактика. 2014. Т. 13, №6. C. 44-50. doi:10.15829/1728-8800-2014-6-44-50

13. De Luca L., Temporelli P.L., Lucci D., et al. Current management and treatment of patients with stable coronary artery diseases presenting to cardiologists in different clinical contexts: A prospective, observational, nationwide study // European Journal of Preventive Cardiology. 2018. Vol. 25, №1. P. 4353. doi:10.1177/2047487317740663

14. Марцевич С.Ю., Захарова Н.А., Кутишенко Н.П., и др. Изучение практики назначения бета-адреноблокаторов и ее соответствия современным клиническим рекомендациям в рамках двух амбулаторных регистров сердечно-сосудистых заболеваний // Рациональная Фармакотерапия в Кардиологии. 2016. Т. 12, №3. С. 260-264. doi:10.20996/1819-6446-2016-12-3-260-264

15. Steg P.G., Ferrari R., Ford I., et al. Heart rate and use of beta-blockers in stable outpatients with coronary artery disease // PLoS One. 2012. Vol. 7, №5. P. e36284. doi:10.1371/journal.pone.0036284

\section{References}

1. Death rates by main chapters of causes. Available at: https://rosstat.gov.ru/bgd/regl/B09_16/IssWWW. exe/Stg/6-08.htm. Accessed: 2020 June 06.

2. Danilov AV, Kobzar II, Nagibin OA, et al. Morbidity and mortality from cardiovascular diseases in Ryazan district: 2014-2018. Nauka Molodykh (Eruditio Juvenium). 2019;7(3):439-49. (In Russ). doi:10. 23888/HMJ201973439-449

3. Sharabchiyev YuT. Vrachebnyye oshibki i defekty okazaniya meditsinskoy pomoshchi: sotsial'no-ekonomicheskiye aspekty i poteri obshchestvennogo zdorov'ya. Mezhdunarodnyye Obzory: Klinicheskaya Praktika I Zdorov'ye. 2013;(6):14-31. (In Russ).

4. Pereverzeva KG, Vorobev AN, Nikulina NN, et al. Features of examination of patients with coronary heart disease in outpatient practice according to observation in a registry study. I.P. Pavlov Russian Medical Biological Herald. 2014;(1):90-6. (In Russ).

5. Otsenka chislennosti postoyannogo naseleniya Ryazanskoy oblasti na 1 yanvarya 2020 goda i v srednem za 2019 god. Available at: https://ryazan.gks.ru/storage/mediabank/Оценка\%20численности\%20постоянного\% 20населения\%20Рязанской\%20области\%20на\%201\%20января\%2020 20\%20года.pdf. Accessed: 2020 June 06.

6. Moy E, Barrett M, Coffey R, et al. Missed diagnoses of acute myocardial infarction in the emergency department: variation by patient and facility characteristics. Diagnosis. 2015;2(1):29-40. doi:10.1515/ dx-2014-0053

7. Sergeev YuD, Bisyuk YuV, Verikovskiy VA. Defects of rendering medical assistance to patients suffering from acute coronary syndrome (medical and legal aspects of the issue). Meditsinskoye Pravo. 2019;(3):31-8. (In Russ).

8. Sergeev YuD, Bisyuk YuV. Some diagnostic defects and their causes in emergency cardiac care. Cardiovascular Therapy and Prevention. 2007; 7(7):67-70. (In Russ).

9. Steg PG, Goldberg RG, Gore JM, et al. Baseline characteristics, management practices, and in-hospital outcomes of patients hospitalized with acute coronary syndromes in the Global Registry of Acute Coronary Events (GRACE). American Journal of Cardiology. 2002;90(4):358-63. doi:10.1016/s0002 -9149(02)02489-X

10. Kaul U, Sethi KK, Dalal J, et al. A multicentre retrospective study to understand anti-platelet treatment patterns and outcomes of acute coronary syndrome 
patients in India (TRACE). Indian Heart Journal. 2014;66(3):334-9. doi:10.1016/j.ihj.2014.03.009

11. Klinicheskiye rekomendatsii «Ostryy infarkt miokarda s pod"yemom segmenta ST elektrokardiogrammy». 2020. Available at: https://scardio.ru/content/Guidelines/2020/Clinic_rekom_OKS_sST.pdf. Accessed: 2020 June 06.

12. Boytsov SA, Luk'yanov MM, Yakushin SS, et al. Cardiovascular diseases registry (RECVAZA): diagnostics, concomitant cardiovascular pathology, comorbidities and treatment in the real outpatientpolyclinic practice. Cardiovascular Therapy and Prevention. 2014;13(6):44-50. (In Russ). doi:10. 15829/1728-8800-2014-6-44-50

13. De Luca L, Temporelli PL, Lucci D, et al. Current management and treatment of patients with stable coronary artery diseases presenting to cardiologists in different clinical contexts: A prospective, observational, nationwide study. European Journal of Preventive Cardiology. 2018;25(1):43-53. doi:10. 1177/2047487317740663

14. Martsevich SYu, Zakharova NA, Kutishenko NP, et al. Practice of prescribing beta-blockers and its compliance with clinical guidelines according to two registers of cardiovascular diseases. Rational Pharmacotherapy in Cardiology. 2016;12(3):260-4. (In Russ). doi:10.20996/1819-6446-2016-12-3-260-264

15. Steg PG, Ferrari R, Ford I, et al. Heart rate and use of beta-blockers in stable outpatients with coronary artery disease. PLoS One. 2012;7(5):e36284. doi:10.1371/journal.pone.0036284

\section{Информация об авторах [Authors Info]}

Колосова Виктория Викторовна - студентка 6 курса лечебного факультета, Рязанский государственный медицинский университет им. акад. И.П. Павлова, Рязань, Российская Федерация.

Victoria V. Kolosova - VI year Student of General Medicine Faculty, Ryazan State Medical University, Ryazan, Russian Federation.

* Мосейчук Ксения Анатольевна - к.м.н., ассистент кафедры поликлинической терапии и профилактической медицины, Рязанский государственный медицинский университет им. акад. И.П. Павлова, Рязань, Российская Федерация.

SPIN: 1297-9721, ORCID ID: 0000-0002-4444-2439. E-mail: ka.moseychuk@ gmail.com

Ksenia A. Moseichuk - MD, PhD, Assistant of the Department of Polyclinic Therapy and Preventive Medicine, Ryazan State Medical University, Ryazan, Russian Federation.

SPIN: 1297-9721, ORCID ID: 0000-0002-4444-2439. E-mail: ka.moseychuk@gmail.com

Паршикова Елена Николаевна - зав. приемным отделением, Люберецкая районная больница №1, Люберцы, Российская Федерация. Elena N. Parshikova - Head of the Admission Ward, Lubertsy Regional Hospital №1, Lubertsy, Russian Federation.

Пыко Андрей Александрович - к.м.н., доцент кафедры факультетской терапии с курсом терапии ФДПО, Рязанский государственный медицинский университет им. акад. И.П. Павлова, Рязань, Российская Федерация.

Andrey A. Pyko - MD, PhD, Associate Professor of the Department of Faculty Therapy with Course of Therapy of Faculty Additional Professional Education, Ryazan State Medical University, Ryazan, Russian Federation.

Урясьев Олег Михайлювич - д.м.н., проф., зав. кафедрой факультетской терапии с курсом терапии ФдПО, Рязанский государственный медицинский университет им. акад. И.П. Павлова, Рязань, Российская Федерация.

SPIN: 7903-4609, ORCID ID: 0000-0001-8693-4696.

Oleg M. Uryasyev - MD, PhD, Head of the Department of Faculty Therapy with Course of Therapy of Faculty Additional Professional Education, Ryazan State Medical University, Ryazan, Russian Federation. SPIN: 7903-4609, ORCID ID: 0000-0001-8693-4696.

Филиппов Евгений Владимирович - д.м.н., доц., зав. кафедрой поликлинической терапии и профилактической медицины, Рязанский государственный медицинский университет им. акад. И.П. Павлова, Рязань, Российская Федерация.

SPIN: 2809-2781; ORCID ID: 0000-0002-7688-7176.

Evgeny V. Filippov - MD, PhD, Associate Professor, Head of the Department of Polyclinic Therapy and Preventive Medicine, Ryazan State Medical University, Ryazan, Russian Federation.

SPIN: 2809-2781, ORCID ID: 0000-0002-7688-7176.

Цитировать: Колосова В.В., Мосейчук К.А., Паршикова Е.Н., Пыко А.А., Урясьев О.М., Филиппов Е.В. Дефекты оказания медицинской помощи пациентам с острым коронарным синдромом с подъемом сегмента ST, не подвергшимся реперфузионной терапии // Наука молодых (Eruditio Juvenium). 2020. Т. 8, №4. С. 531-540. doi:10.23888/HMJ202084531-540

To cite this article: Kolosova VV, Moseichuk KA, Parshikova EN, Pyko AA, Uryasyev OM, Filippov EV. Defects of providing medical care to patients with ST segment elevation acute coronary syndrome who did not receive reperfusion therapy. Science of the young (Eruditio Juvenium). 2020;8(4):531-40. doi:10.23888/HMJ202084531-540

Поступила / Received: 06.06.2020

Принята в печать / Accepted: 01.12.2020 